\title{
Envisioning Co-Existence: Exploring Responses to Migration in Mohsin Hamid's Exit West
} Jaspreet Singh Research Scholar, Department of English, Central University of Himachal Pradesh, Dharamshala (HP), India
jaspreetsivian87@gmail.com

\begin{abstract}
Migration is one of the most influential contemporary phenomena. With its Mass effects, migration is shaping the social fabrics, geopolitical positions, and paradigms of the world politics. Literature being a reflection and a product of its surrounding material conditions is also continuously depicting, analysing, comprehending and engaging with the phenomenon of migration. The presentpaper also aims at exploring the nature of the conflict of native-migrant, and possible alternatives to resolve this conflict as depicted in Mohsin Hamid's Exit West (2017). The text deals with the life of a young couple living in an unnamed city of an Asian country facing civil war. Thetext outlines their migrations due to the outbreak of war in their city.They in search of stable living conditions move from one to another place throughout the world, including Mykoons, London and San Francisco and the US. The text depicts their experiences as migrants in these places.An attempt will be made to analyse the phenomenon of Migration and experiences of Migrants. The study will further explore the narrative of the text to understand the dynamic positions of the characters in a binary framework of native and migrant. The study will extrapolate how the status of being migrantprioritize the ideas of survival.The study will further unravelthe struggles and efforts of the displaced human beings to reshape, reorganize their lives in new paradigms, and how displacement is not only limited to physical space but also affects the mental and social spaces. The paper will further investigate the role of harmonious living in the times of such mass level migrations.
\end{abstract}

Keywords-Co-existence, Harmony, Displacement, Migrant, Marginality, Survival.

\section{INTRODUCTION}

Migration is a phenomenon as old as human civilization. It was through migration that human race spread across this globe from the place of their origin. Before being civilized, human race survived as a tramp roaming in the wild forests, mountains, and plains. But in the modern world with particular stringent geo-political boundaries, with the creation of nations and other geopolitical entities, the phenomenon of migration has completely transformed. As Soren Frank declares "twentieth-century age of migration" and this phenomenon has seen further growth in these two decades of the twenty-first century. Frank enumerates multiple factors including "two world wars, regional wars, the process of decolonization emergence of totalitarianism regimes" etc. behind this large scale migration of twentieth and twentyfirst century. This flux of refugees, migrants, and exiles have resulted in significant changes in particular societies and on humanity in general (Frank, 1). As with so many other important factors, the phenomenon of migration has been studied extensively in different academic spheres be it History, Anthropology, Sociology, etc. Literature being a product of human activity has reflected upon migration from various aspects. Many literary works from ancient to contemporary works have depicted migration as a multifarious thematic concern. This depiction of migration and the extensive unravelling of the experiences of migrants through their own writing and through the writing of others in literature paves the way for theoretical constructs like hybridity and diaspora. This paper aims at exploring Exit West a novel by Pakistani Expatriate British author Mohsin Hamid for analysing the experience of being migrant, and effects of migration or displacement on natives and migrants, through the response of various characters of the select text.

The beginning of the text indicates towards the recurrence of migration as a major thematic concern. The first meeting of Nadia and Saeed, the protagonist couple, takes place in an unnamed "city swollen by refugees" (Hamid 1).The narrator of the text immediately indicates at one prominent casual of migration war. The city is "still mostly at peace, or at least not yet openly at war" (Hamid 1). Hamid's description of Saeed's residence again echoes this fear of war which from a "slight premium place in during gentler times' turns into 'most undesirable in times of conflict" (Hamid8). This extrapolation of the 
relationship of war and migration echoes through the text, founding family of a Chinese restaurant in which they meet, was "migrated to this city due to WWII" and they have "emigrated further to Canada" after an escalation in the civil war going in their county (Hamid 19). The looming danger of war finds expressions in their realization that "War Soon erode the façade of their building as though it had accelerated time itself, a day's toll outpacing that of a decade" (Hamid 19). Hamid through referring to the effect of this war comments on contemporary world politics in regard to the refugee crisis. The narrator of text records, for international entities "war, was doing badly" as "unprecedented flow of migrants" and their response to the situation of "building walls and fences strengthening their borders" turning to be futile exercise (Hamid 71). The text intensifies the fear and destruction of war with details of firing, bombing, curfews, killings, etc. The narrator unravels the transformation of routine life when infected with the violence of war. This atmosphere of uncertainty, violence and chaos paves way for the migration of Saeed and Nadia along with many others.

Hamid, with a touch of magic realism, has used the device of 'magical doors' for the transportation of his protagonist couple and other migrants. Hamid makes use of this device of magical doorsto avoid the details of physical hardships faced by migrants in their movement from one place to another. Further through this use of 'magical doors' he has also tried to depict migration as a universal phenomenon caused by various factors.In the text not only Saeed and Nadia migrate from their city to Greece, England and the United States but there are others also - two Filipina girls moving to Tokyo, A too dark man arriving in Australia etc. These movements of various people belonging to different social hierarchies, from various places symbolise the universality of human migration. Further, these magical doors metaphorically represent shifts in the lives and identities of these migrants. These doors which are full of dark and migrants coming out of these doors represent troubled places in terms of social, political or economic affairs to which these migrants belong. The position of exit points ofthese doors into dark alleys or into deserted homes etc. represents the new status or the marginality of migrants in these new places.

Another important psychological trait among many of migrants is their desire to preserve their distinctive identity be it cultural or religious; contrary to this few of them try to absorb or assimilate the host cultural milieu. In Exit West, Saeed represents the former trait and Nadia represents the latter trait. Saeed turns more introvert after moving from their native city. He always tries to get associated with people of his community and even after ending his relationship Nadia, he again turns toward another woman from his community. His dressing style becomes more conventional according to his community tradition. He starts praying daily with more devotion. For Saeed prayer serves as a tool to connect with his parents, the narrator recounts, "He prayed fundamentally as a gesture of love for what had gone and would go and could be loved in no other way" (Hamid201). Furthermore, in his quest for the survival of his distinctive identity prayer represents his connection with his roots:

...about being a man, being one of the men, a ritual that connected him to adulthood and to the notion of being a particular sort of man, a gentleman, a gentle man, a man who stood for community and faith and kindnessand decency, a man, in other words, like his father. (Hamid, 200)

Saeed becomes suspicious of other migrants who have also come with them through magical doors. His insecurity as an outside grows more prompts him to own a revolver. On the other hand, Nadia becomes more adventurous, more open towards another fellow human being without holding any bias regarding community, creed, etc. her friendship with the Greek volunteer girl, her association and her active participation in Nigerian migrants who are also living in the same mansion and eventually her relationship with a Cook represents her lineage to assimilate traits of the host culture.

The text also extrapolates about the status of migrants and natives, and further emergence of conflict among those groups. Unnamed city to which Saeed and Nadia belong also faces flux of migration due to the ongoing war in the other parts of their country. Description of those migrants occupying "open places in the city, pitching tents in green belts, erecting lean-tos next to the boundary wall of houses" (Hamid 23) not only expresses their adverse conditions as outsiders to the city. It further contrasts symbolically by turning places of leisure and relaxation of city natives into places of survival for the migrants. Among all this chaos they still try to "recreate the rhythms of normal life"(Hamid 23) depicts the intrinsic intuition of survival in an adversary. Their mixed feelings towards the city as outsiders are depicted as "they stare at the city, with anger, or surprise, or supplication or envy" (Hamid 24). Migrants feeling of being outsidersechoes throughout the text as Saeed and Nadia leaves behind wartorn country and travel to more stable developed countries and as their own status turns into migrants they share the same feelings. Saeed and Nadia after going through a 
magical door from the Greek Island of Mykoons find themselves in an empty mansion in London with many other migrants from various parts of the world. Those migrants occupying the house successfully resist the police action aimed at evacuating them from that mansion. The conflict of native and migrant emerges to its full extent when nativist mob attacks these migrants. The atmosphere of fear and uncertainty grips all those living in a mansion. The narrator further recounts the intensification of the conflict and it turns into a movement of, "reclaim Britain for Britain". Deployment of Army, police and ex-army men as trained volunteers makes the situation worse (Hamid 132) it points out the restrictions has been put on the migrants in terms of movement, work, etc. by metaphorically diving London in light London and dark London. And how the dark London witness acute surveillance, "as drones and helicopters and surveillance balloons" (Hamid 133) prowls in the sky of London. This tension escalates and stays there for many days and both groups remain on the brink of acute violence and bloodshed. The increasing understanding of the need forexistence put this conflict behind. As the narrator recounts, "perhaps they had grasped that doors could not be closed and new doors would continue to open" and "denial of coexistence" is futile and furthermore they cannot withstand their coming generations if they do that is required for making migrants extinct (Hamid 164). Hamid contemplating upon the sad state of contemporary politics, wars, and crisis extrapolates basic human instinct of survival on any cost in any condition and hopes for a better future:

...the apocalypse appeared to have arrived and yet it was not apocalyptic, which is to say that while the changes were jarring they were not the end, and people found things to do and ways to be and people to be with, and plausible desirable futures began to emerge, unimaginable previously, but not unimaginable now. (Hamid215)

Through this journey of Nadia and Saeed from this unnamed city to various parts of the world, Hamid encapsulates their changing social, political lineage and how their personalities undergo a holistic transformation. The text not only depicts their migration but by incorporating the same kinds of instances of migration happening in far off places like Australia, Dubai author intends to propound the ideas of migration as a universal phenomenon of our contemporary times. In the text, most of the characters are in movement from one place to another. The text-only brings forth the plight of migrants who are running away from war, violence, uncertainty to western countries but as a consequence of being migrant, their marginalized status puts them in the same kind of situation.

Exit West is a unique text in its treatment of the phenomenon of migration. Hamid through delignating migrants experience, their encounters with new cultures, societies and responses of natives emerged out of these encounter provides acomprehensive understanding of the migration in our contemporary times. It further promotes the idea of co-existence and aims at attaining a better understanding of fellow human being by going beyond borders and boundaries. On a philosophical level texts puts forth our human life as a kind of migration as with time our dynamic personalities undergo subtle changes and one never remains the same. The title of the text also intrigues the reader in the at first title seems to refers to the migration of Saeed and Nadia as well as others to the Western Countries. But going deeper it symbolizesthe required change in the policy of western countries regarding migrants. It represents an exit from the policy of conflict.It propounds the idea of coexistence as theonly plausible solution for the survival and betterment of humanity.

\section{REFERENCES}

[1] Frank, Soren. Migration and Literature. Palgrave \& Macmillan, 2008.

[2] Hamid, Mohsin. Exit West. Penguin Random House, 2017.

[3] Kakutani, Michiko. 'Review: In 'Exit West,' Mohsin Hamid Mixes Global Trouble With a Bit of magic."New York Times, Feb 27. 2017. www.nytimes.com/2017/02/27/books/review-exit-westmohsin-hamid.html, Accessed. 25 Jun 2018. 